\title{
The Formulation of Vertical Jump Height Measurement As The Basis for Developing Leg Power Test Instrument
}

\author{
Sri Haryono ${ }^{1}$, Sugiyanto ${ }^{2}$, Agus Kristiyanto ${ }^{3}$, Risa Suryana ${ }^{4}$ \\ \{ sriharyono@student.uns.ac.id ${ }^{1}$, sugiyantoprobo@gmail.com ${ }^{2}$, aguskriss@yahoo.co.id ${ }^{3}$ \} \\ Universitas Sebelas Maret, Surakarta, Indonesia ${ }^{123}$
}

\begin{abstract}
In some sports movement, leg strength plays an important role in supporting sports activities. Vertical jump height is often used as an indicator of leg strength. The objective was to create an effective formula for measuring vertical jump height as a basis for developing a leg power test instrument. Research and development method with a model from Borg and Gall in carrying out this research was used. Testing the validity of this research is by comparing the results of measuring jump height using the vertical jump test, DF jump test and prototype, as well as a re-test for reliability testing. The analyze was used ANOVA. The results showed that the coefficient of validity for a jump with an arm swing was 0.69 and for a jump without an arm swing was 0.77 , and reliability was 0.97 . The research concluded that the formula developed is effective enough to measure jump height as a basis for developing leg power test instruments. The reviewed needs to provide more effective results.
\end{abstract}

Keywords: Formula, jump height, leg power.

\section{Introduction}

Until now, Indonesia hasn't yet become a country that can produce many international class athletes that can be renowned around the world. This encourages the importance of developing science and technology in sports. Several sports that often achieve maximum achievements in singles /multi events at the international level have also not been able to be consistently maintained. Efforts to produce athletes who are able to obtain the best performance must not only go through a good coaching process but also must be supported by the application of science and technology as well. At this time the role of sports science and technology is very important in an effort to improve sports achievement and advance the sports of a nation. Finnsgard stated that the current application of sports science and technology is an inseparable part of efforts to foster elite sports and help optimize the potential of athletes [1].

The application of science and technology in sports achievements can be used by coaches and athletes to support the training process in order to get maximum training results. So far, manufacturers of sports technology equipment have originated and been developed by other countries which have elite sports, such as America, France, Germany, China and Japan. Indonesia as a developing country has not applied much science and technology in the process of fostering national sports. This is due to the limited national budget to meet the needs of science and technology as well as limited human resources [2]. 
One of the benefits of sports technology products is to make it easier for coaches to carry out sports evaluation programs, especially measuring the capacity of athletes and one of them is leg power. Leg power is needed by athletes in several sports, including athletics, swimming, basketball, soccer, volleyball, badminton, tennis, sepaktakraw, baseball, martial arts, and others. So far, the measurement of leg power has been carried out by connecting the results of the jump height test, which is carried out through the vertical jump test [3]. This test can be done quite easily and cheaply, but it has a weakness in the meter board that is installed in a vertical plane such as walls and poles that coincide with the board, so that the testee cannot perform the movement optimally since they are afraid if the legs or other body parts hit the wall. Another weakness is that it requires careful observation by the tester to see the results for the jump height [4].

Another test use that uses a more modern measuring instrument is the Jump DF which was developed using a touch sensor on a plate connected to a recording machine [5]. After the testee stands and jumps on the plate, the display box will show the results of the jump height achieved. However, to have this tool requires a large amount of funds. The price for 1 set of Jump DF TKK-5414 series produced by Takei company Japan is IDR 125,000,000.00. Based on the description related to the use of instruments for measuring jump height, the authors conducted research aimed at developing a formula for measuring jump height with a digital system. The problem in this research is how is the formula to measure the jump height with a valid digital system? The output in this study produces a formula for measuring the jump height with a valid digital system .

\section{Methods}

Researchers used research and development methods with a research and development model from Walter R. Borg, Meredith Damien Gall, and Joyce P. Gall which consisted of 10 stages, namely [6]; 1) research and information collecting, 2) planning, 3) develop preliminary form of product, 4) preliminary field testing, 5) main product revision, 6) main field testing, 7) operational product revision, 8) operational field testing, 9 ) final product revision, and 10) dissemination and implementation [7], which can be described as a research and development design as seen in figure 1 .

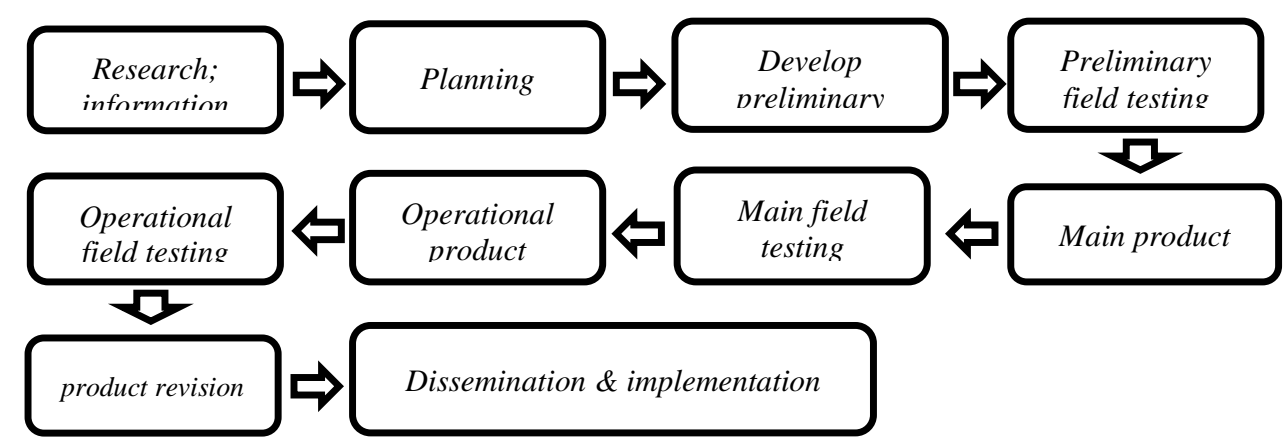

Fig. 1. The design of jump measurement formula development with digital system 
Small-scale and large-scale testing was conducted at the Sports Test and Measurement Laboratory at the Faculty of Sports Science, Semarang State University. Meanwhile, the laboratory which is the center of the Robotics Team of UNNES is an expert partner in the field of electronics for the development of formulas for measuring jump height based on digital systems. Sources of data were obtained from the results of field tests with the subjects of volleyball, basketball, and athletic athletes who were all 13 students of the Faculty of Sport Science, Semarang State University. Formula validity testing was done by comparing the results of measuring the jump height using the vertical jump test with the vertical board and jump DF. Data analysis was performed by using ANOVA statistic [8].

\section{Results}

The results of the developed formula consist of 5 stages which can be explained as follows; Stage 1 : Weighing the body, in order to obtain $m_{\text {jumper }}$,

Stage 2 : the jump made will cause pressure on the plate so that the plate gets pressure which can be formulated as follows; $F_{\text {pressure }}=m . g$, in which $F_{\text {pressure }}=$ downward force, $m=$ maximun load of downward pressure, and $g=$ gravity

Stage 3 : the jumper is in the air, so that the value of force is obtained $m$. When the jumper has left the surface of the plate automatically there is no pressure on the plate, so that the change in force is obtained from the maximum pressing time until takeoff and can be seen in the formula: $F=m . a$, in which $F=$ upward force (to get back to normal),

$m=m_{\text {jumper }}$ (the weight of the jumper we get in stage 1 ), and $a=$ acceleration. $F$ is the upward return force from the plate to return to normal conditions, where this force is pointing upwards so that there is an acceleration effect $(a)$. Meanwhile, the load received by the plate during this stage is the weight of the jumper $\left(m_{\text {peloncat }}\right)$. From the formula above, because this force runs from the maximum pressing time until the plate has no more pressure, it can be formulated as follows: $F=m . a$, because there is a time lag $t$ so $: F . t=m . a . t$ or : [9]

$\int_{t_{1}}^{t_{2}} F_{\text {Jumper }}(t) d t=m$.a. $t$, it can beconsidered that $v=$ a.t so $: \int_{t_{1}}^{t_{2}} F_{\text {Jumper }}(t) d t=m . v$

While taking off :

$$
\begin{aligned}
& F_{\text {pressure }}=\int_{t_{1}}^{t_{2}} F_{\text {Jumper }}(t) d t \\
& \text { m.g }=m_{\text {jumper }} \cdot \text { a.t } \\
& a=\frac{m \cdot g}{m_{\text {jumper }} \cdot t}
\end{aligned}
$$

Stage 4 : Calculating the predicted altitude. After $\mathrm{v}$ is known, then kinetic and potential energy analysis can be used with the following formula,

$$
\begin{aligned}
& K E_{t o}+P E_{t o}=K E_{p}+P E_{p} \\
& 1 / 2 \mathrm{~m} \cdot V_{t o}^{2}+\mathrm{m} \cdot \mathrm{g} \cdot h_{t o}=1 / 2 \mathrm{~m} \cdot V_{p}^{2}+\mathrm{m} \cdot \mathrm{g} \cdot h_{p}
\end{aligned}
$$

Because in this condition all usem peloncat , so $m$ on the right and left can be crossed out, so that;

$$
\begin{aligned}
& 1 / 2 V_{t o}^{2}+\mathrm{g} \cdot h_{t o}=1 / 2 V_{p}^{2}+\mathrm{g} \cdot h_{p}, \\
& 1 / 2 V_{t o}^{2}+\mathrm{g} \cdot h_{t o}=\mathrm{g} \cdot h_{p} \\
& \text { g. } h_{p}-\mathrm{g} \cdot h_{t o}=1 / 2 V_{t o}^{2}
\end{aligned}
$$




$$
h_{p}-h_{t o}=\frac{v_{t o}^{2}}{2 \cdot g}
$$

Since $h_{t o}$ considered to be zero ( 0 ), because the height is calculated from the height of the jump toward the plate, then the initial height is plate, so that it can be written:

$$
h=\frac{v_{t o}^{2}}{2 . g} \text {, since } V_{t o}=v \text { obtained from the previous equation, it can be written: } h=\frac{V^{2}}{2 . g}
$$

Stage 5 : Jumper landing. When the jumper lands, there will be a significant increase in pressure on the plate, which indicates that the jumper has made a landing. This change is a sign to show the results of the estimated jump height that can be done based on the formula developed above.

From the results of the development of the formula for measuring the jump height above, then a test is carried out to measure the ability of the jump height [10]. The results of measurements using 3 types of instruments, namely the vertical jumpt test board, jump DF test and vertical jump prototype both with arm swing and without arm swing as in table 1 . Measurement result data with 2 other instruments are used to test the validity of the developed formula.

Table 1. The results of the jump height measurement with 3 test instruments

\begin{tabular}{ccccccc}
\hline & \multicolumn{2}{c}{ Board Vertical Jump Test $(\mathrm{cm})$} & \multicolumn{2}{c}{ Jump DF Test $(\mathrm{cm})$} & \multicolumn{2}{c}{$\begin{array}{c}\text { Vertical Jump Prototype } \\
(\mathrm{cm})\end{array}$} \\
\cline { 2 - 7 } Nb. & $\begin{array}{c}\text { With arms } \\
\text { swing }\end{array}$ & $\begin{array}{c}\text { Without arms } \\
\text { swing }\end{array}$ & $\begin{array}{c}\text { With arms } \\
\text { swing }\end{array}$ & $\begin{array}{c}\text { Without } \\
\text { arms swing }\end{array}$ & $\begin{array}{c}\text { With arms } \\
\text { swing }\end{array}$ & $\begin{array}{c}\text { Without } \\
\text { arms swing }\end{array}$ \\
\hline S.1 & 57 & 40 & 61 & 51 & 41,99 & 54,21 \\
S.2 & 76 & 74 & 83 & 77 & 48,13 & 52,09 \\
S.3 & 58 & 50 & 66 & 61 & 33,06 & 52,84 \\
S.4 & 62 & 65 & 67 & 61 & 56,89 & 37,75 \\
S.5 & 62 & 58 & 70 & 61 & 50,57 & 49,16 \\
S.6 & 39 & 32 & 47 & 39 & 39,64 & 38,91 \\
S.7 & 35 & 30 & 43 & 39 & 47,16 & 43,10 \\
S.8 & 50 & 42 & 51 & 46 & 48,11 & 53,03 \\
S.9 & 36 & 30 & 44 & 42 & 46,36 & 44,90 \\
S.10 & 37 & 35 & 43 & 42 & 43,95 & 35,71 \\
S.11 & 48 & 42 & 49 & 47 & 50,78 & 28,59 \\
S.12 & 45 & 42 & 50 & 40 & 50,70 & 54,26 \\
S.13 & 43 & 38 & 46 & 40 & 34,71 & 34,06 \\
\hline
\end{tabular}

Based on the data from the measurement results of the jump height with the 3 instruments in table 1 above, a comparison of the measurement results is obtained which can be seen in Figure 2 (a) and (b). 


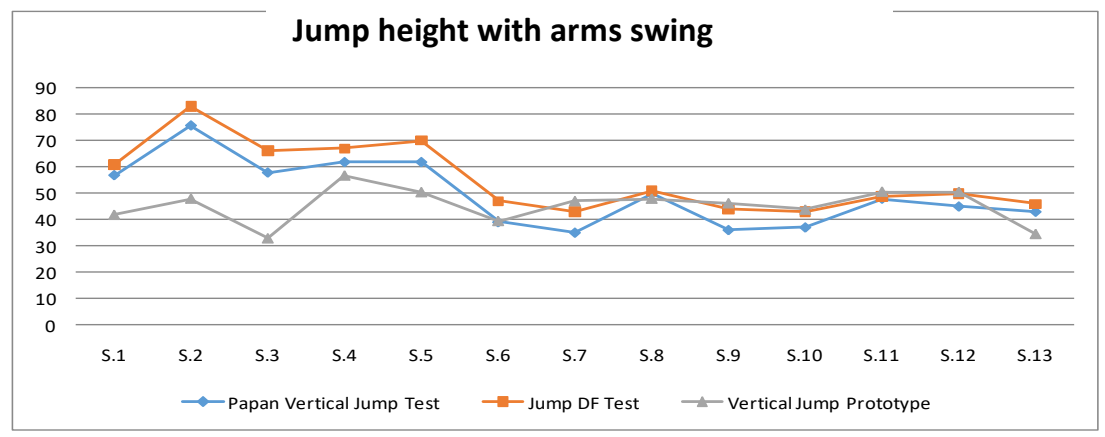

(a)

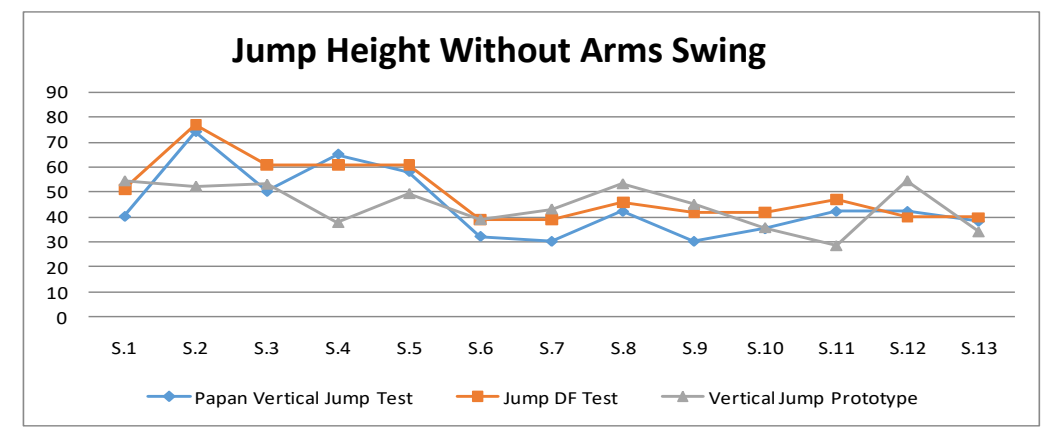

(b)

Fig. 2. Comparison of data from the measurement of jump height of 3 types test instruments (a) with arms swing and (b) without arms swing

Furthermore, the data from the measurement of jump height from 3 types of test instruments were analyzed with ANOVA statistics which aims to determine the correlation and used as a parameter to determine the validity coefficient of the formula developed to measure the jump height. As seen in Table 2 below, it is known that the validity coefficient is 0.69 for the arms swing test and 0.77 for without arm swing test [11].

Table 2. The results of the validity test using ANOVA

\begin{tabular}{ccc}
\hline \multicolumn{1}{c}{ Test Variable } & \multicolumn{2}{c}{ Coefficient of Validty } \\
& With Arms Swing & Without Arms Swing \\
\hline $\begin{array}{l}\text { Vertical Jump Test (VJT)) - Jump DF Test } \\
\text { (JDF) - Vertical Jump Prototype (VJP) }\end{array}$ & 0.69 & 0.77 \\
\hline
\end{tabular}




\section{Discussion}

Paying attention to the test results of the formula for measuring the jump height, the validity coefficient was obtained which comprised 0.69 and 0.77 , so it can be concluded that the formula developed for the test involving the motion of arms swing was still in a low validity level or was questionable (0.60-0.69), while the test without arms swing was acceptable or acceptable (0.700.79). Therefore, in order to make the formula applicable to an instrument for measuring jump height or leg power, it is necessary to make further improvements and adjustments so that a higher coefficient of validity can be obtained (0.80-0.84) with the very good validity category.

\section{Conclusion}

Based on the result and discussion, it can be concluded that the formula designed to measure the jump height in this study is considered to be questionable since the coeficient validity of the test has not gained the standard of validity test. Therefore, a further study needs to be conducted to make it more valid.

\section{References}

[1] Baumgartner, TA. and Jackson, AS. Measurement For Evaluation In Physical Education and Exercise Science, Fourth Edition, Printed in the United States of America : Wm. C. Brown Communications, Inc. 1995.

[2] Finnsgard C. How Sports Can Create New Knowledge at a Technical University that Claim not Doing Research in Sport Science?. Proceeding of Sports Science Research and Technology Support. 2015. DOI 10.1007/978-3-319-52770-3

[3] Fraden J. Handbook Of Modern Sensors. New York: Springer Link. 2004.

[4] Gall, M.D., Gall, J.P. and Borg, W.R. Educational Research an Introduction. 8th Edition, Pearson. 2007.

[5] Jones, P., \& Jones, A. Attitudes of Sports Development and Sports Management Undergraduate Students Towards Entrepreneurship: A University Perspective Towards Best Practice. Education + Training. 2014. 56 (8/9), 716-732. https://doi.org/http://dx.doi.org/10.1108/ET-06-2014-0060

[6] Linthorne, N. P. Analysis of standing vertical jumps using a force platform, American Journal of Physics. 2001; 69: 1198-1204.

[7] Mc. Ginnis, Peter M. Biomechanics of Sport and Exercise. Second Edition. Printed in the United States of America : Human Kinetics. 2005.

[8] Ratten, V. 2018. Sports Innovation Management. New York : Routledge. 2018. https://doi.org/10.4324/9781315177977-1

[9] Roetert, Paul and Ellenbecker, Todd S. Complete Conditioning for Tenis. Printed in the United States of America : Human Kinetics. 1998.

[10] Sri Haryono, dkk. Pengembangan Jump Power Meter sebagai Alat Pengukur Power Tungkai. Jurnal Iptek Olahraga. 2013; 15(1):1-17.

[11] Ujihashi, S. Sports Technology and Engineering. In The Impact of Technology on Sport II (pp. $3-$ 11). London: Taylor \& Francis/Balkema. 2007. 